\title{
Estudo comparativo de conforto térmico em praças de São Carlos-SP
}

\section{Comparative study of thermal comfort in squares of São Carlos-SP}

\author{
Fernandes, Maria Eugênia'; Bellei, Bianca Sobrinho2; Fonseca, André Luiz \\ Amorim da 3 ; Pedro Bon, Frederico4; Carvalho, Wanessa Karoline Maciel5; \\ Oliveira, Djanny Klismara de 6 ; Kowalski, Luiz Fernando7; Corrêa, Rony Felipe \\ Marcelino8; Masiero, Érico?.
}

\author{
1 Universidade Federal de São Carlos - UFSCAR, Rod. Washington Luiz, 235, \\ São Carlos - SP, Brasil. fernandes.me88@gmail.com?. \\ 2 Universidade Federal de São Carlos - UFSCAR, biancabellei@hotmail.com. \\ ${ }^{3}$ Instituto Federal de Educação, Ciência e Tecnologia de Mato Grosso, \\ andre.fonseca@cba.ifmt.edu.br. \\ ${ }^{4}$ Universidade Federal de São Carlos - UFSCAR, fredericoej@gmail.com. \\ 5 Universidade Federal de São Carlos - UFSCAR, \\ wanessacarvalho29@gmail.com. \\ 6Universidade Federal de São Cárlos - UFSCAR, djanny215@gmail.com. \\ 7 Universidade Federal de São Carlos - UFSCAR, \\ fernando.kowalski@ucb.org.br. \\ 8 Universidade Federal de São Carlos - UFSCAR, ronycorrea@hotmail.com. \\ 9 Universidade Federal de São Carlos - UFSCAR, erico@ufscar.br.
}

\begin{abstract}
RESUMO
Para uma análise microclimática e de conforto térmico no espaço urbano podem-se empregar diferentes técnicas de coleta e instrumentação. O objetivo deste trabalho é estudar o efeito de diferentes densidades de arborização no conforto térmico do pedestre em duas praças de São Carlos - SP. O conforto térmico dos usuários foi avaliado efetuando um comparativo entre as duas praças, com a aplicação da Temperatura Fisiológica Equivalente (PET - Physiological Equivalent Temperature). Foram utilizados dataloggers para registro da temperatura e umidade do ar, da temperatura de globo e da velocidade do vento na camada intra-urbana, além de coleta de imagens termográficas simultâneas as entrevistas com usuários durante o período mais quente de um dia típico de inverno. Os resultados mostram que, embora a diferença microclimática entre as áreas analisadas seja pequena, a Praça dos Voluntários (Área A) apresentou melhores condições de conforto no inverno. No entanto, os usuários mostraram maior satisfação na Praça da Catedral (Área B), o que pode ser motivado pelo vento, que apresentou maiores velocidades na Área A.
\end{abstract}

1 FERNANDES, Maria Eugênia; BELLEI, Bianca; FONSECA, André Luiz Amorim da; BON, Frederico Pedro; CARVALHO, Wanessa Karoline Maciel; OLIVEIRA, Djanny Klismara de; KOWALSKI, Luiz Fernando; CORRÊA, Rony Felipe Marcelino; MASIERO, Érico. Estudo comparativo de conforto térmico em praças de São Carlos-SP. In: II SIMPÓSIO NACIONAL DE GESTÃO E ENGENHARIA URBANA: SINGEURB, 2019, São Paulo. Anais... Porto Alegre: ANTAC, 2019. 
Palavras-chave: Conforto térmico urbano, Climatologia urbana, Instrumentação em clima e conforto térmico urbano.

\begin{abstract}
For a microclimatic analysis and thermal comfort in the urban space different techniques of collection and instrumentation can be used. The objective of this work is to study the effect of different densities of afforestation on thermal comfort of the pedestrian in two squares of São Carlos - SP. The thermal comfort was evaluated, comparing the two squares, with the application of Physiological Equivalent Temperature (PET). Dataloggers were used to record temperature and air humidity, globe temperature and wind speed in the intra-urban layer, as well as the collection of thermographic images, simultaneous with interviews with users during the hottest period of a typical winter day. The results show that, although the microclimatic difference between the analyzed areas is small, Area A presented better comfort conditions in winter. However, users showed greater satisfaction in Area B, which may be motivated by higher wind speeds in Area A.
\end{abstract}

Keywords: Urban thermal comfort, Urban climatology, Instrumentation in urban climate and thermal comfort.

\title{
1 INTRODUÇÃO
}

Desde a revolução industrial, os problemas decorrentes da dificuldade de se implantar medidas adequadas de planejamento urbano vêm causando prejuízos à qualidade de vida devido ao crescimento urbano desordenado. Com a demanda de novas áreas habitacionais e industriais, as cidades apontam cada vez menos áreas verdes e permeáveis (MIGUEL et al., 2009).

Segundo Givoni (1976; 1992), a substituição do solo natural por materiais impermeáveis modifica as propriedades térmicas da superfície, alterando as trocas térmicas entre esta e o meio, e a grande concentração de edifícios, automóveis e indústrias altera a circulação do ar no interior das cidades, gerando aumento na produção de calor e desconforto para a população (ABREU, 2008).

Oke (2006) explica a influência das superfícies no microclima e no entorno imediato, sendo que a temperatura da superfície e do ar podem variar vários graus até em distâncias curtas. Oke (1989) também afirma que as árvores têm potencial para agirem como modificadoras do clima urbano, e para Shashua-Bar e Hoffman (1999), as áreas verdes urbanas são significativas em diferentes tamanhos, formas e morfologia, pois cada área apresenta uma qualidade térmica diferente, e seu efeito no ambiente é expressivo, mesmo se for pequeno.

Rossi, Kruger e Nikolopoulou (2011) afirmam que o conforto térmico em espaços urbanos abertos pode influenciar positivamente 0 uso e o comportamento das pessoas, pela qualidade térmica que eles apresentam. Nikolopoulou et al. (2001), ressaltam a riqueza de características microclimáticas em espaços urbanos abertos e áreas vegetadas e as implicações de conforto para as pessoas que as utilizam.

O conforto térmico é determinado pela combinação de variáveis pessoais (taxa metabólica, isolamento térmico da vestimenta) e ambientais (temperatura radiante média, umidade relativa, temperatura e a velocidade do ar), fatores que interferem no sistema termorregulador (FROTA e SCHIFFER, 2003; JOHANSSON, 2014). A principal condição para se obter conforto térmico é que o corpo humano esteja em equilíbrio térmico, (RUAS, 2001; LAMBERTS E XAVIER, 2013).

\section{OBJETIVO}

O objetivo deste trabalho é estudar o efeito de diferentes densidades de arborização no conforto térmico do pedestre em duas praças de São Carlos - SP. 


\section{MATERIAIS E MÉTODOS EMPREGADOS}

A metodologia adotada nesta pesquisa dividiu-se em três etapas apresentadas na figura 1 e descritas posteriormente:

Figura 1- Fluxograma metodológico.

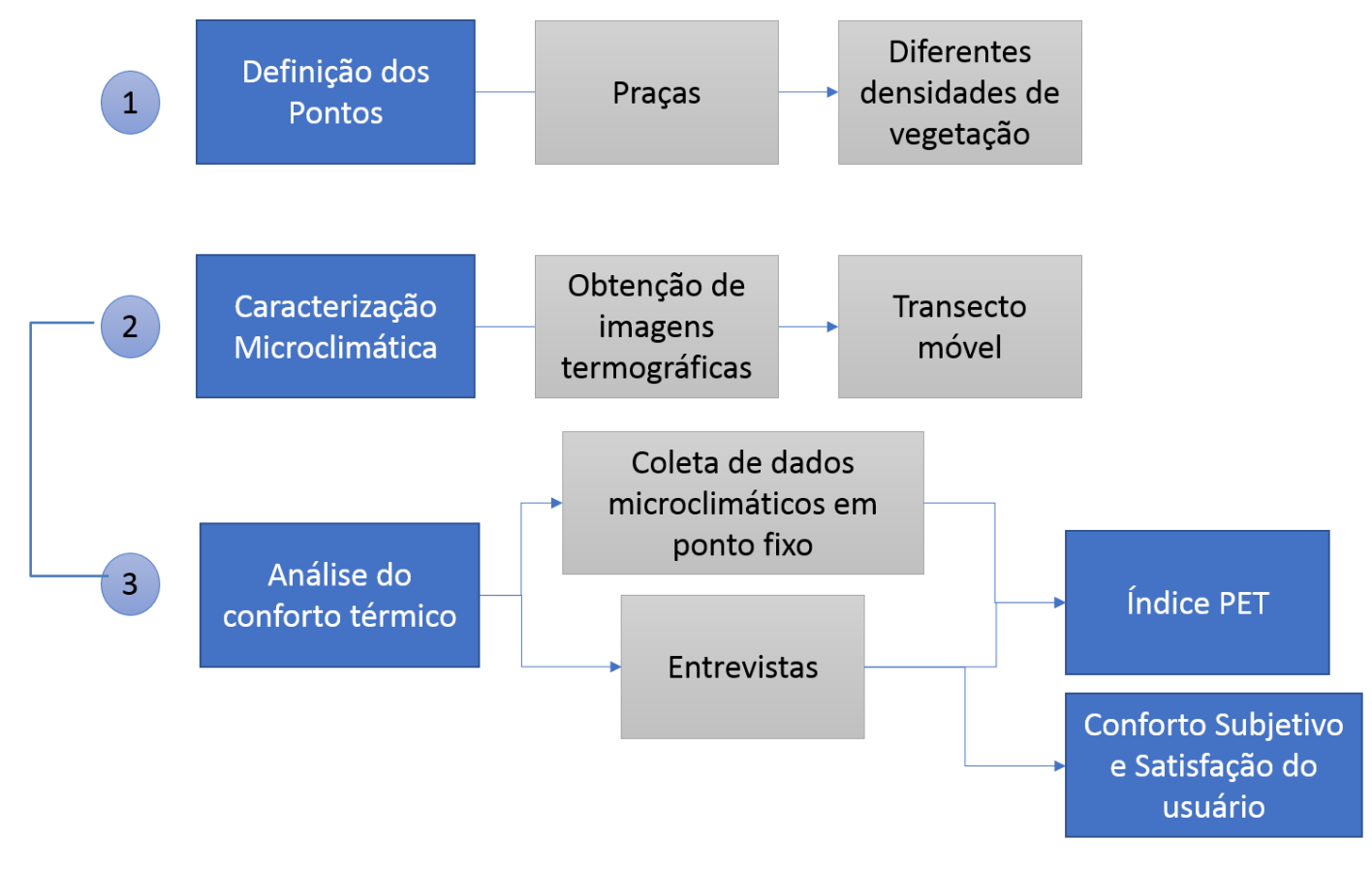

Fonte: Os Autores

\subsection{Definição dos pontos}

Foram selecionados dois recortes na área central da cidade de São Carlos-SP com fluxo intenso de pessoas e automóveis, formados pela Praça Maria Apparecida Resitano e Praça dos Voluntários, denominada "Área A", e a Praça da Catedral e Praça Coronel Paulino Botelho, denominada "Área B" (Figura 2b).

Os pontos se diferem pela quantidade de vegetação, sendo a área A constituída por pouca vegetação esparsa, grande quantidade de área impermeável e construída e a área $B$ constituída por um maciço de vegetação e uma edificação. 
Figura 2- (a) Localização da área de estudo na cidade; (b) Recortes analisados.

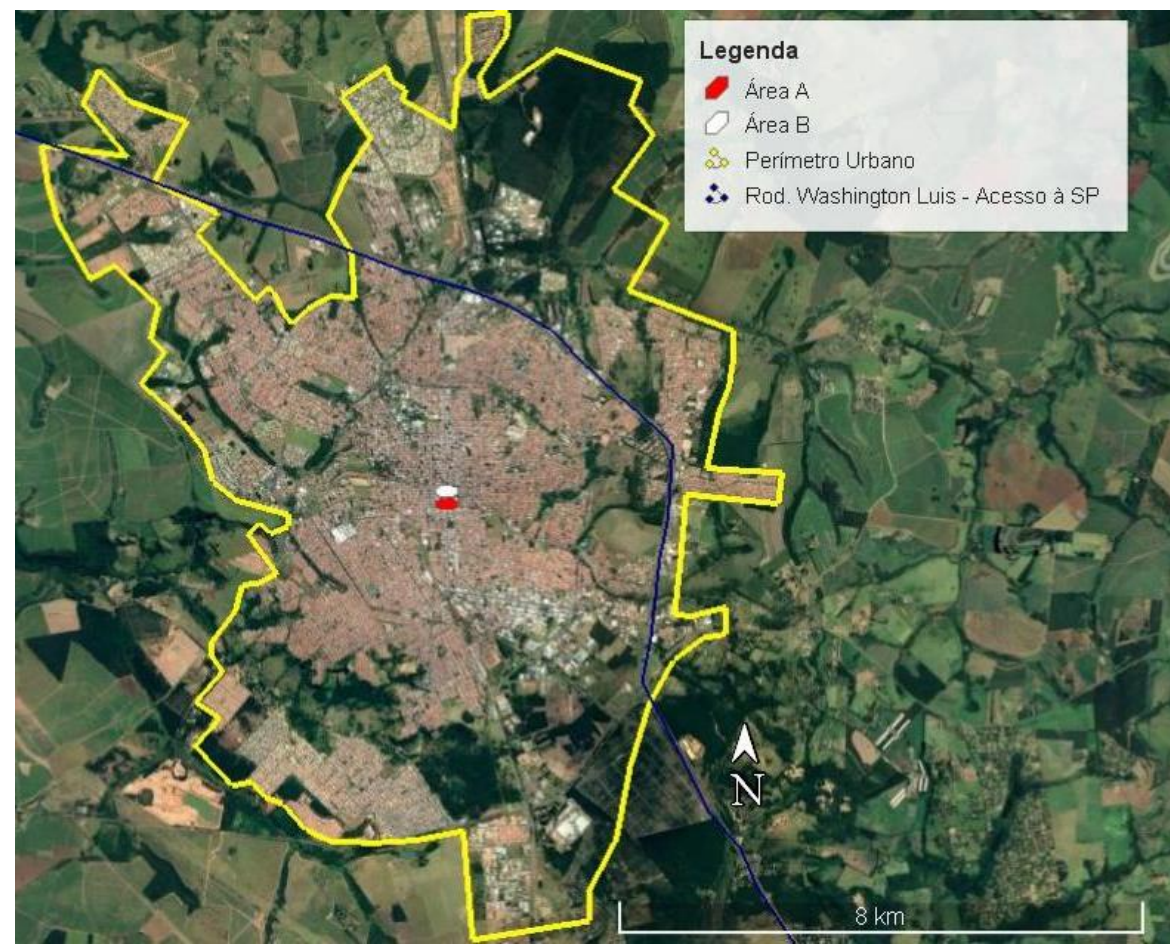

(a)

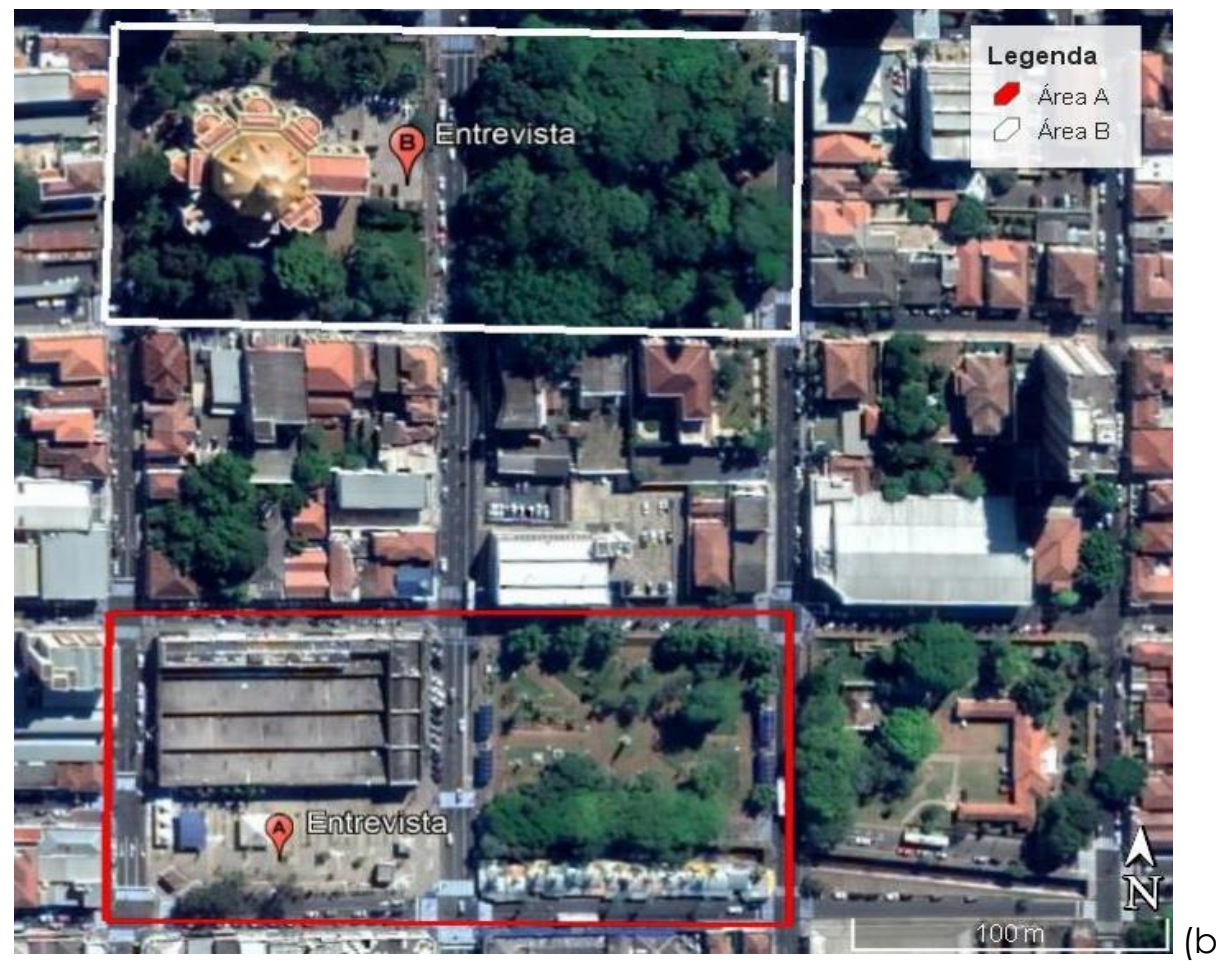

Fonte: Adapt. Google Earth, 2018

As etapas 3.2 e 3.3 foram realizadas simultaneamente no dia 27 de agosto de 2018, com céu claro e vento fraco, no período de inverno das $15 \mathrm{~h}$ às $16 \mathrm{~h}$.

\subsection{Caracterização microclimática}

Visando caracterizar o microclima do entorno imediato das áreas analisadas foi realizado um transecto móvel e coleta de imagens termográficas. 
- Transecto móvel

Para analisar a variação de temperatura do ar e umidade relativa do ar (UR), foi realizado um transecto móvel utilizando um termo-higrômetro Hobo (Figura 3a) acoplado em escudo (Figura 3b), para evitar influência da radiação solar direta.

Figura 3 - (a) datalogger Hobo Pro V2; (b) Abrigo em PVC.

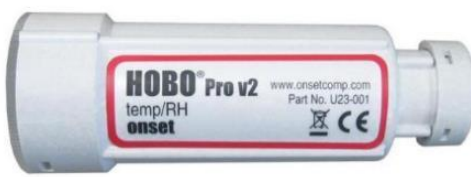

(a)

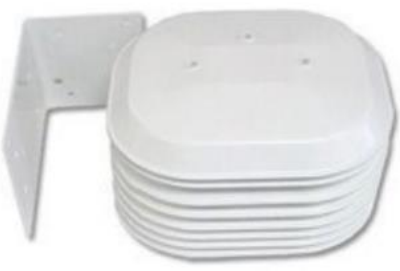

(b)

Fonte: Onset Comp., 2019.

O trajeto de medição passou por 5 quadras do centro de São Carlos-SP, atravessando perpendicularmente a Área A. Foram medidos 3 pontos em cada quadra (Figura 4), com leituras de aproximadamente 2 minutos por ponto, a cerca de 1,5m do solo. Esse trajeto foi realizado simultaneamente com a aplicação de entrevistas para os usuários das áreas $A$ e $B$, para analisar o conforto térmico, e com a coleta de dados climáticos também nessas áreas.

Figura 4 - Pontos de medição do transecto móvel.

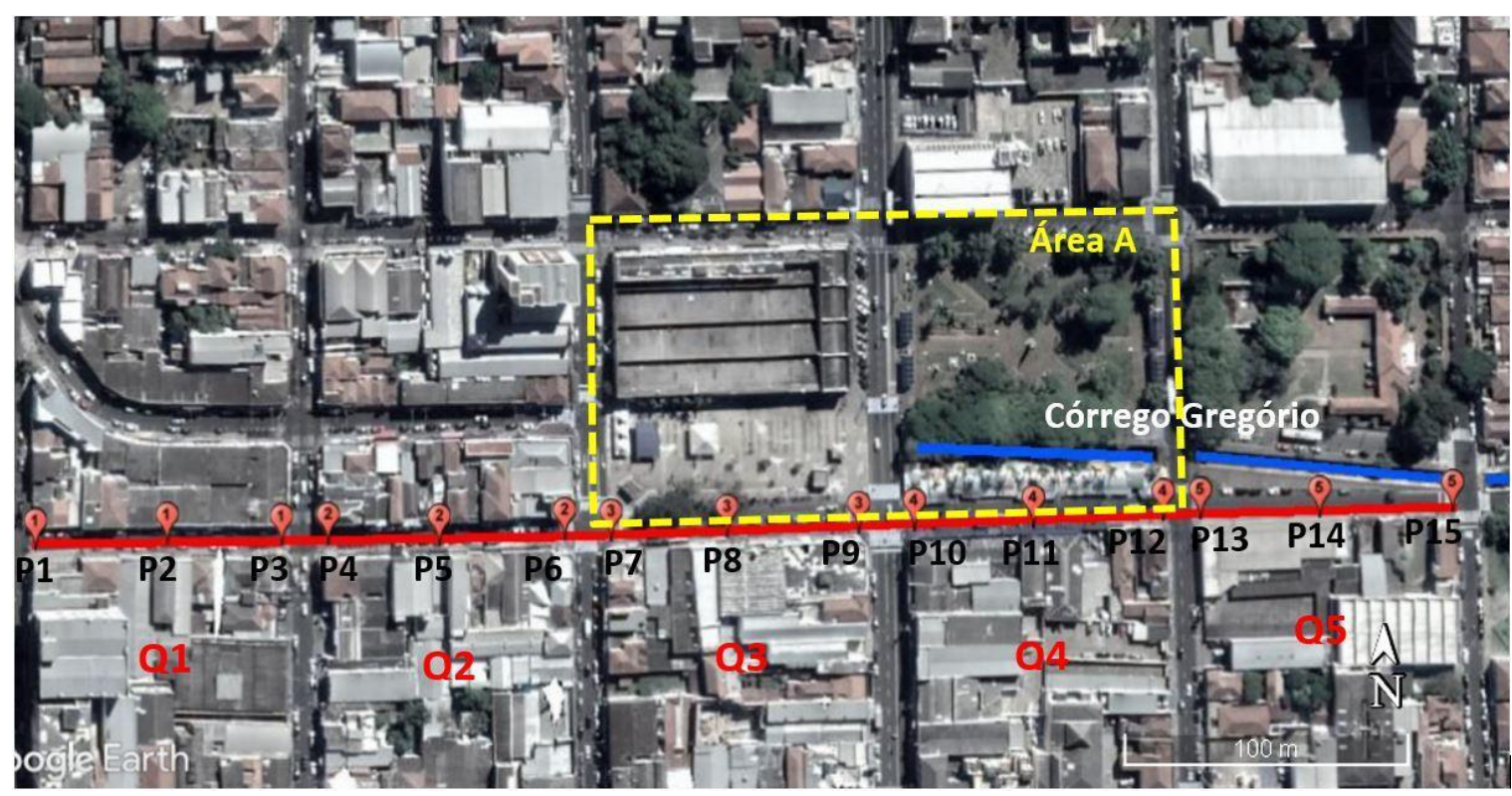

Fonte: Adapt. Google Earth, 2018.

- Imagens termográficas

Para que seja ilustrada de maneira sucinta a influência da arborização nas duas áreas em estudo foram feitas imagens termográficas (Figura 5). 
Figura 5 - (a) Câmera de infravermelho Fluke; (b) Aplicação em campo.

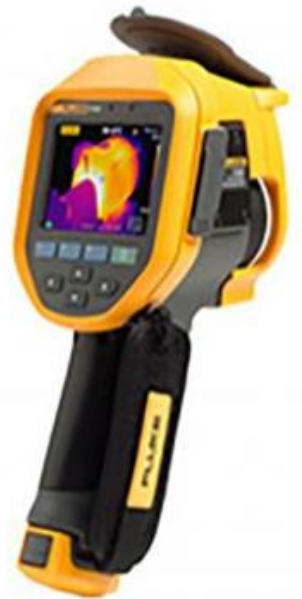

(a)

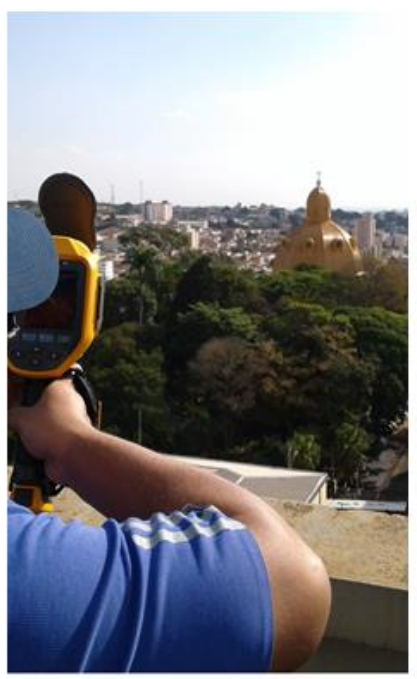

(b)

Fonte:(a) Fluke, 2019; (b) Autoria própria, 2018.

As imagens foram obtidas a partir da cobertura do Edifício José D'Luca Sobrinho (Área A) e Edifício Bandeirantes (Área B), conforme a figura 6. O ângulo de inclinação da câmera foi de aproximadamente $15^{\circ}$ na direção das regiões em estudo, dentro das limitações impostas pela localização das coberturas dos prédios nos quais as fotos foram feitas, e que foi permitido acesso.

Figura 6- Pontos de captura das imagens termográficas.

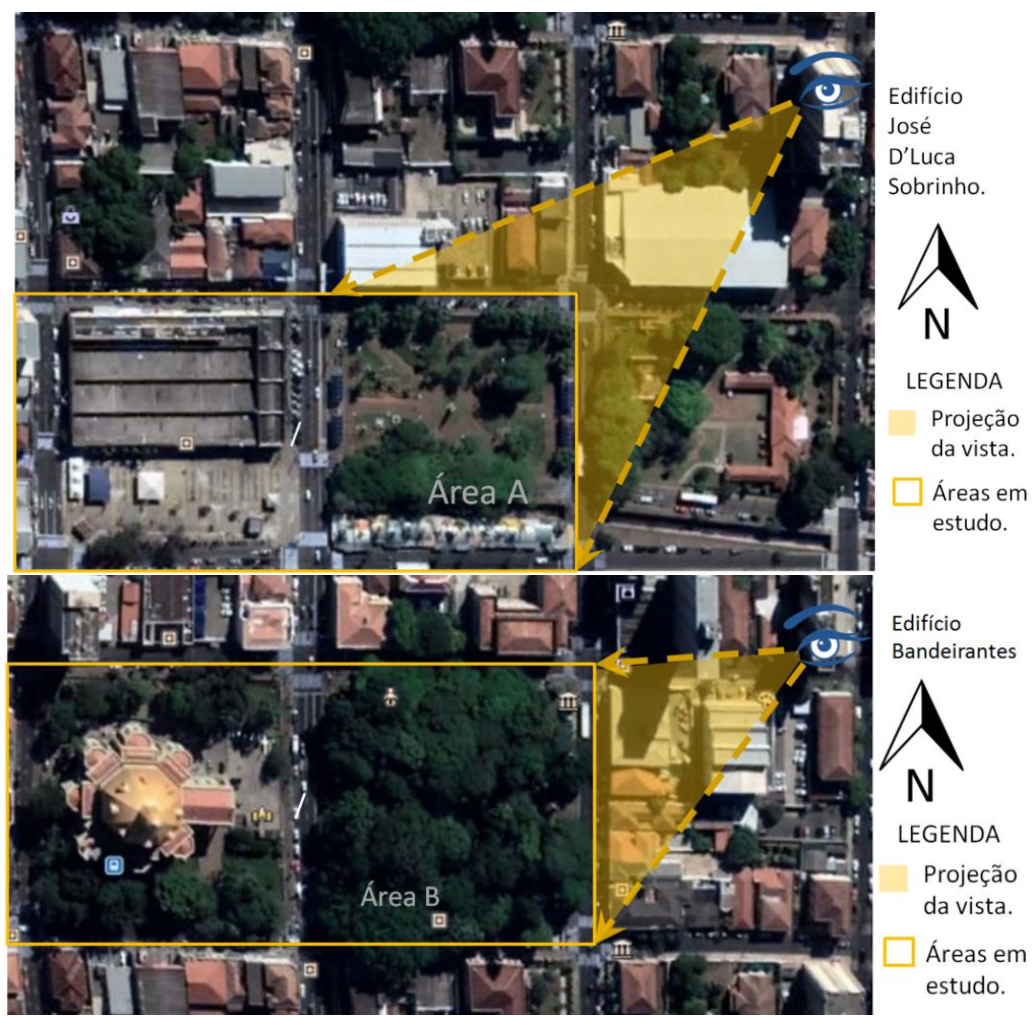

Fonte: Adapt. Google Maps, 2018. 


\subsection{Análise do conforto térmico e satisfação dos usuários}

Para analisar o conforto térmico utilizou-se o índice PET - Temperatura Fisiológica Equivalente (Physiological Equivalent Temperature), desenvolvido por Hoppe (1999), que considera não só a temperatura, umidade e vento, mas também a temperatura radiante média e é baseado na equação de equilíbrio térmico humano em estado de uniformidade (MAYER \& HÖPPE, 1987).

Para a medição da temperatura do ar e UR do ar foi utilizado um Hobo Pro V2, conforme figura $3 a$ e 3b. A velocidade do vento foi medida com o Anemômetro Digital de Bolso (figura 7a) e a temperatura de globo utilizando um termômetro de globo feito a partir do termoanemômetro Kimo VT200 (Figura 7b), com o sensor posicionado no interior de uma esfera com diâmetro $D=40 \mathrm{~mm}$ pintada na cor cinza médio (Figura $7 \mathrm{c}$ ). Os equipamentos foram montados em um tripé a cerca de $1,5 \mathrm{~m}$ do solo.

Figura 7 - (a) Anemômetro Lutron LM-81 AM; (b) Termo-anemômetro Kimo; (c) Termo-anemômetro Kimo adaptado.

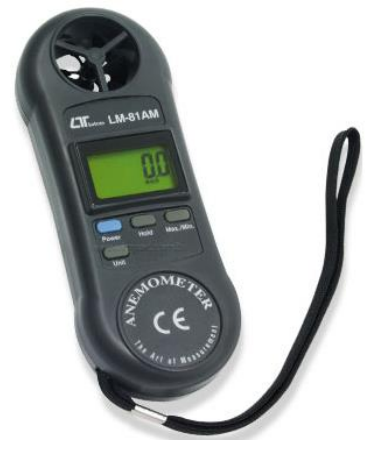

(a)

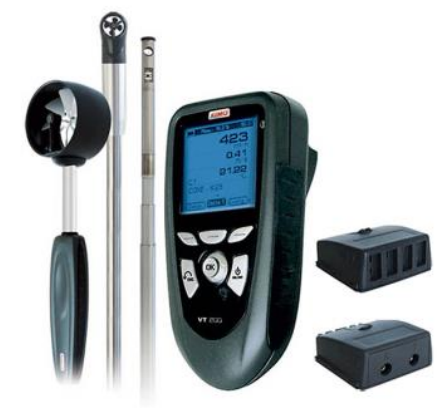

(b)

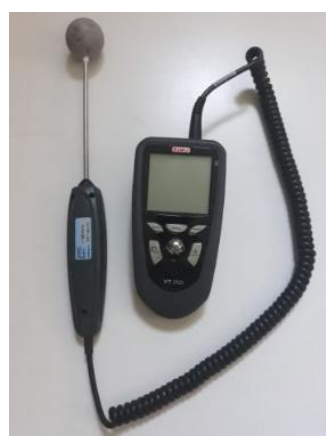

(c)

Fonte: (a): Impac, 2019 (b): Genesys analítica, 2019 (c) Autoria própria, 2019.

Foram realizadas entrevistas com os usuários visando obter informações pessoais, como: idade, peso, altura, coeficiente de isolamento térmico da vestimenta (CLO) e taxa metabólica (MET).

As entrevistas investigaram também a percepção térmica dos usuários, utilizando uma escala de sete pontos (Muito quente, quente, morno, neutro, fresco, frio e muito frio) e a satisfação com o ambiente térmico, utilizando uma escala de cinco pontos (Muito insatisfeito, insatisfeito, indiferente, satisfeito e muito satisfeito).

A amostragem foi definida considerando o maior número de usuários encontrados nos locais nesse intervalo. Foram realizadas 24 entrevistas na área $\mathrm{A}$ e 30 na área $\mathrm{B}$, totalizando 54 indivíduos, dos quais $59 \%$ do sexo masculino e $41 \%$ feminino, com idade variando de 20 a 81 anos, peso médio de $79 \mathrm{~kg}$ e altura $1,70 \mathrm{~m}$.

A partir dos valores obtidos, o cálculo do índice PET foi realizado através do programa computacional Rayman 1.2 (UNIVERSITÄT FREIBURG, 2009).

\section{APRESENTAÇÃO E ANÁLISE DOS RESULTADOS}

A seguir, os dados serão apresentados graficamente de modo a efetuar um comparativo entre as áreas. 


\subsection{Caracterização microclimática}

O transecto móvel mostrou pequena variação de temperatura na região. A Figura 8 mostra um leve resfriamento a medida em que se aproxima das quadras com vegetação e do Córrego do Gregório (Quadra 5).

Figura 8 - Variação de temperatura do ar e UR do ar durante o transecto.

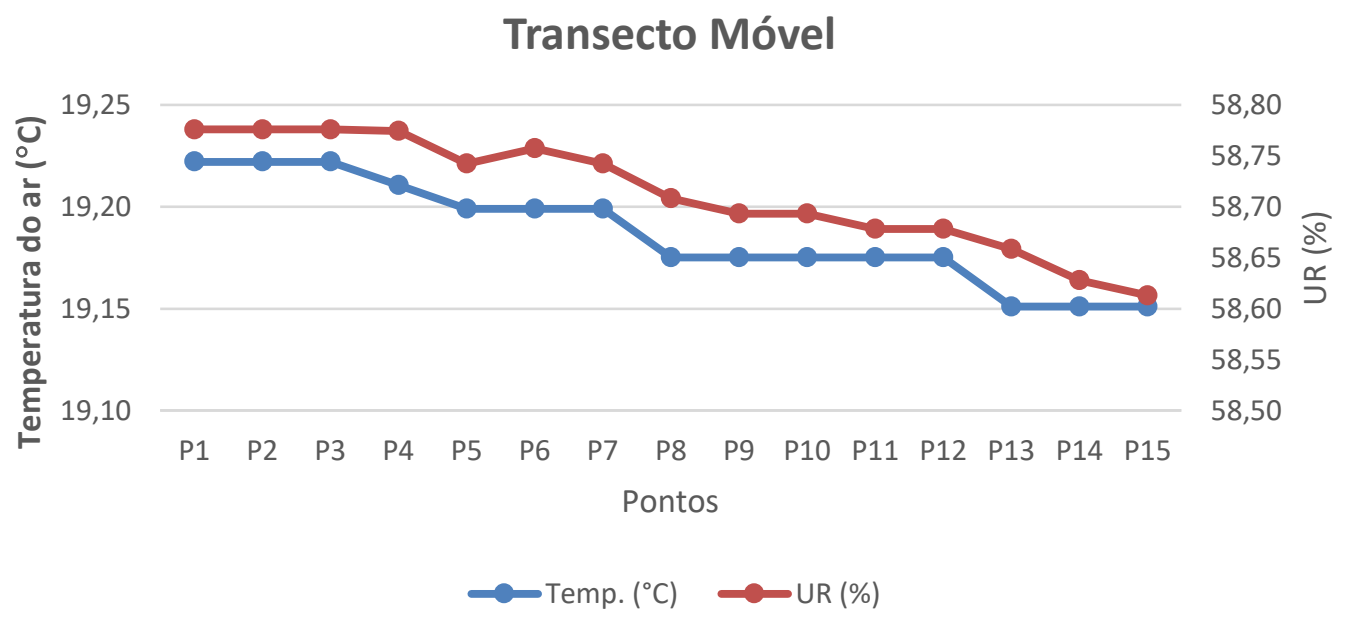

Fonte: Os autores, 2019.

A partir das imagens termográficas verificou-se grande diferença entre os máximos de temperatura das superfícies das áreas analisadas. A Área A apresenta uma temperatura máxima de $42,3^{\circ} \mathrm{C}$ (Figura 9).

Figura 9 - Visualização comum e termográfica da Área A.

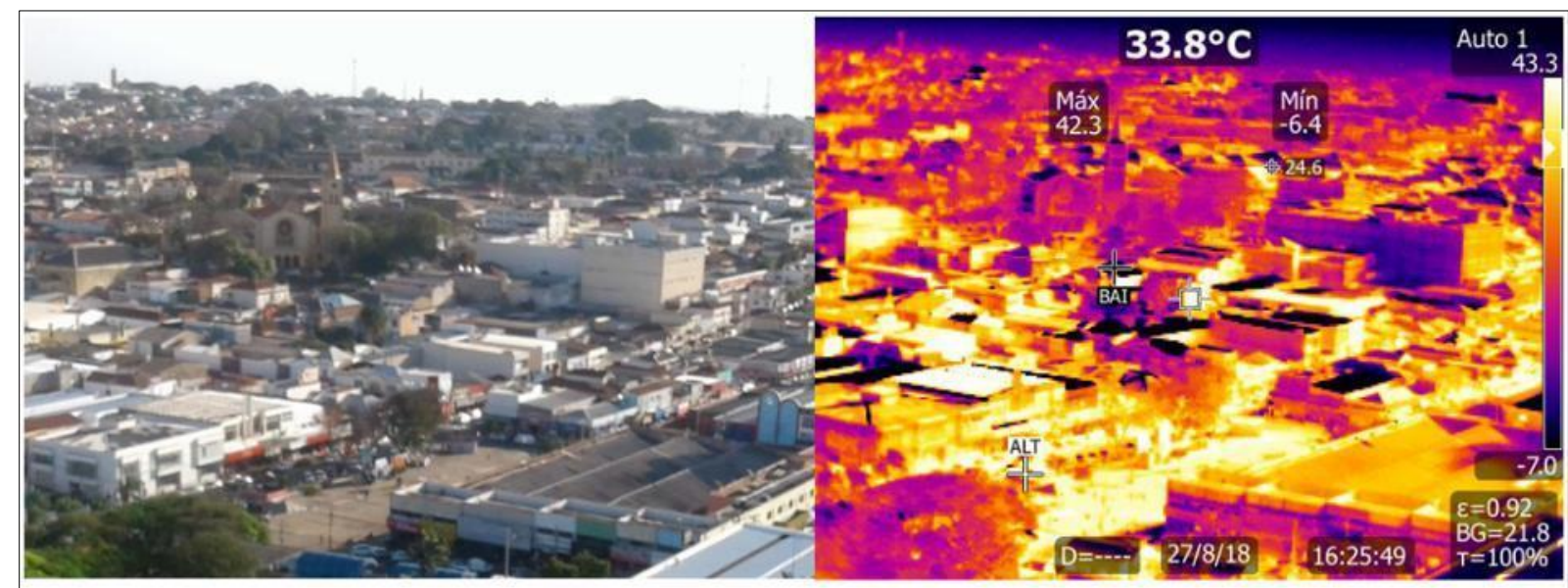

Fonte: Os autores, 2018.

A Área B apresenta temperatura máxima de superfície de $30,2^{\circ} \mathrm{C}$, aproximadamente $12,1^{\circ} \mathrm{C}$ inferior a temperatura da Área A (Figura 10). Na Área B, a maciça arborização dificultou a obtenção da temperatura superficial, entretanto observa-se que esta é altamente sombreada e possui influência da evapotranspiração das árvores em seu microclima. 
Figura 10- Visualização comum e termográfica da Área B.

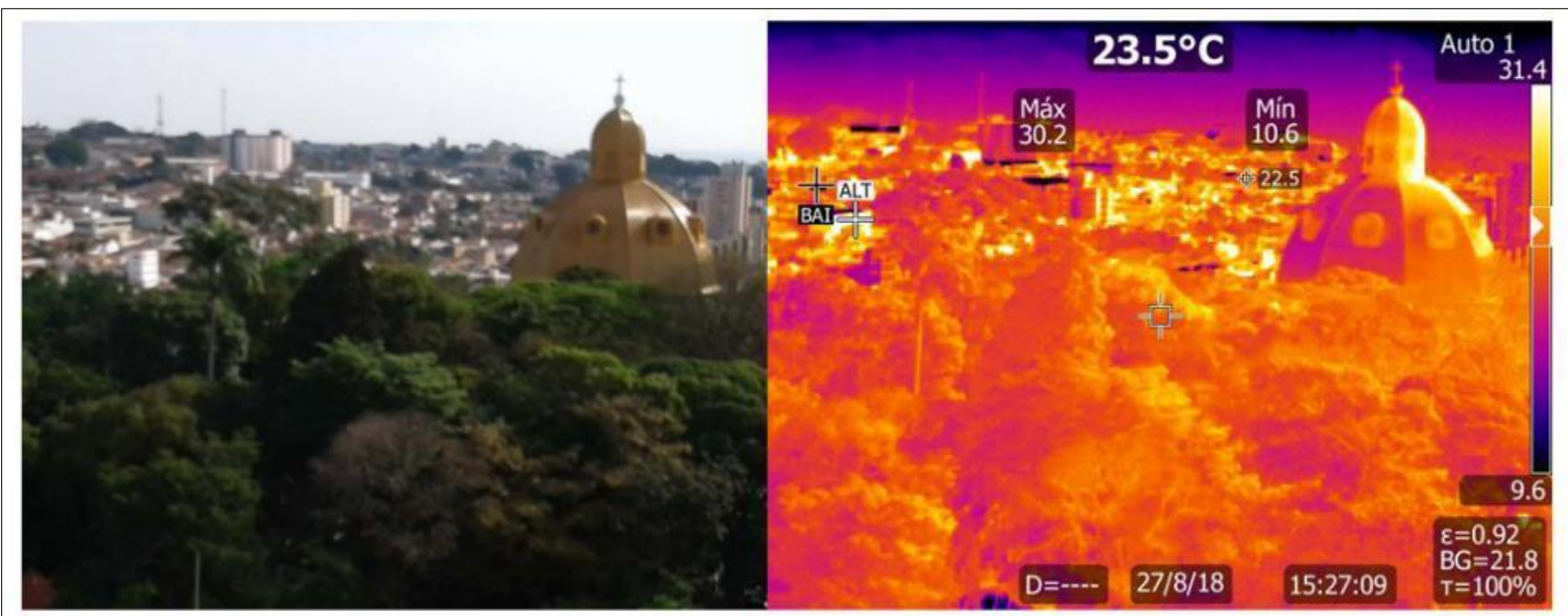

Fonte: Os autores, 2018

Observa-se que alguns pontos atingiram temperaturas negativas. O manual de instruções do fabricante da câmera alerta para discrepâncias nos resultados provocadas por superfícies de baixa emissividade.

\subsection{Conforto térmico e satisfação dos usuários}

A Figura 11 apresenta a índice de conforto calculado nas duas áreas analisadas.

Figura 11 - PET - comparativo entre as praças.

Comparativo de PET

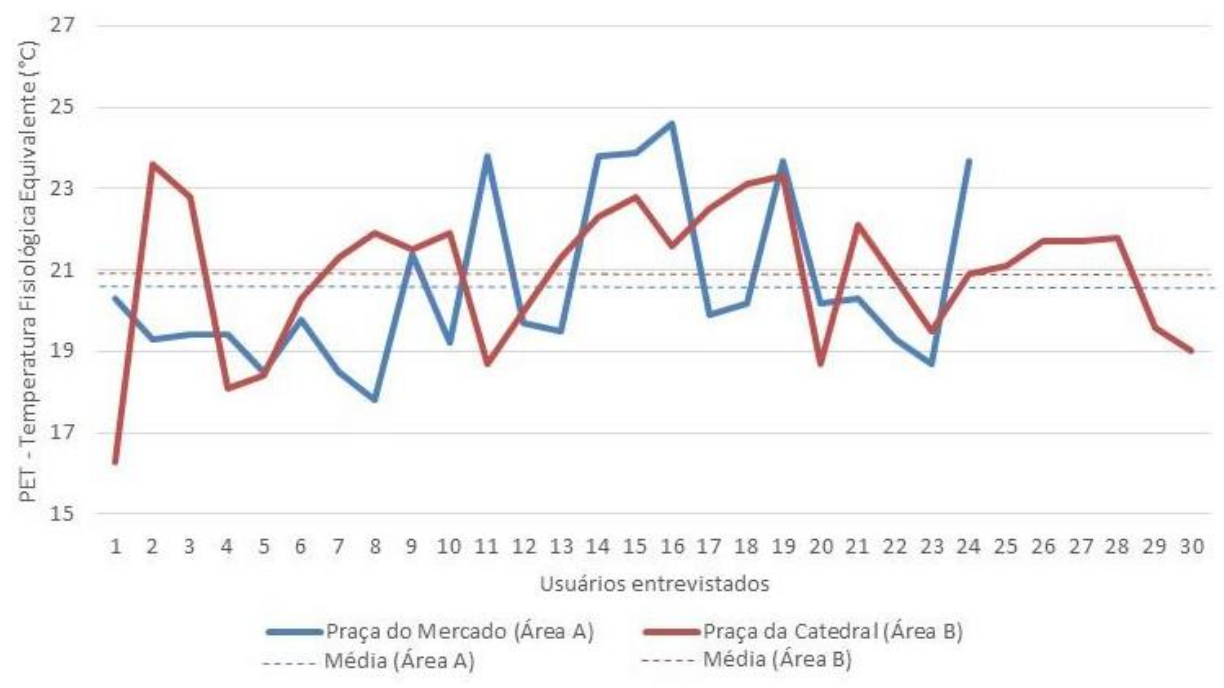

Fonte: Os autores, 2019

A Área A alcançou valores mais altos de PET, variando de $17,8^{\circ} \mathrm{C}$ a $24,6^{\circ} \mathrm{C}$, enquanto a Área $\mathrm{B}$ variou de $16,3^{\circ} \mathrm{C}$ a $23,6^{\circ} \mathrm{C}$. No entanto, o valor médio $\left(20,6^{\circ} \mathrm{C}\right.$ - área $\mathrm{A}$ e $20,9^{\circ} \mathrm{C}$ - área $\left.\mathrm{B}\right)$ de PET apresentou resultado semelhante nos pontos, o que pode estar relacionado à proximidade entre as áreas.

Adotando-se a calibração proposta por Monteiro e Alucci (2010) para a cidade de São Paulo, nota-se que os pontos estão, predominantemente, na faixa de neutralidade térmica. 
A Figura 12 apresenta a percepção térmica dos usuários nas duas áreas estudadas.

Figura 12 - Percepção dos usuários - comparativo entre as praças.

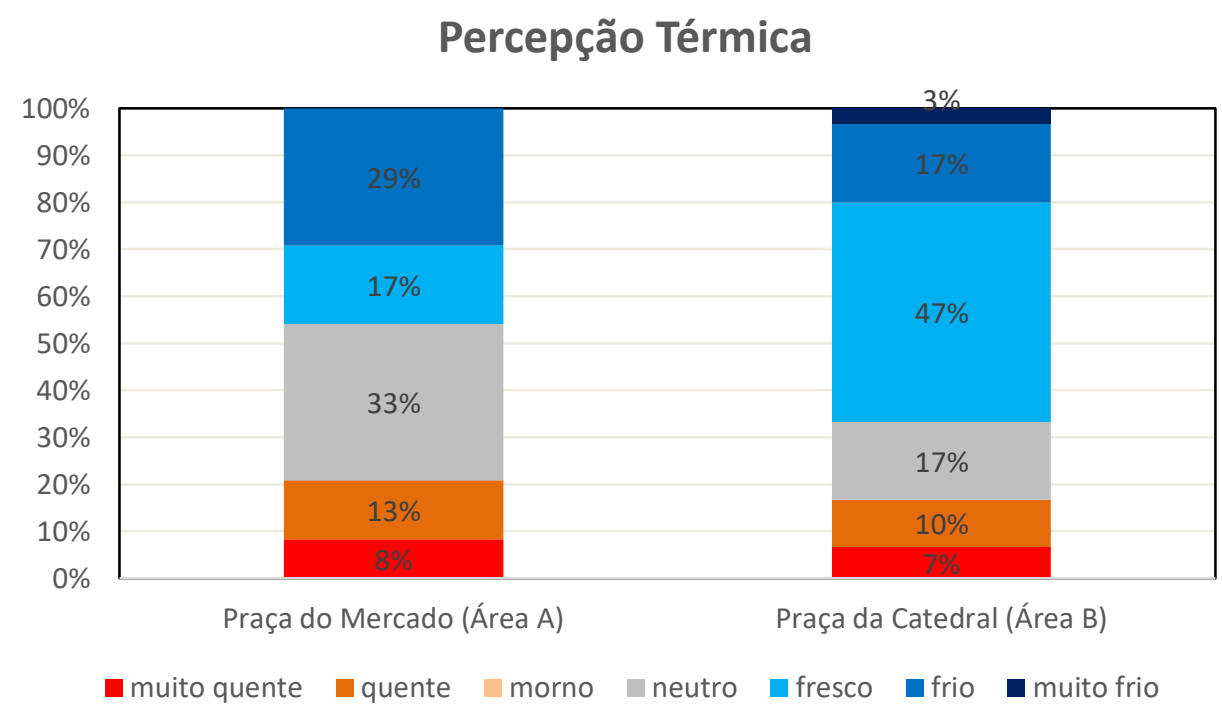

Fonte: Os autores, 2019.

Na Área A, a maioria dos usuários relatou neutralidade térmica, condizente com o índice calculado, no entanto, uma grande parcela de usuários $(29 \%)$ informou sentir frio. Na Área B, $47 \%$ dos votos foram para a percepção "Fresco".

A Área A possui pouca arborização e grande quantidade de área impermeável, favorecendo o acúmulo de calor, o que pode proporcionar boas condições de conforto durante as estações frias. No entanto, durante o período de verão, Fernandes e Masiero (2018) detectaram desconforto por calor e grande insatisfação dos usuários nessa área.

A Figura 13 apresenta o percentual de satisfação dos entrevistados com o ambiente térmico em cada uma das áreas.

Figura 13- Satisfação - comparativo entre as praças.

\section{Satisfação}

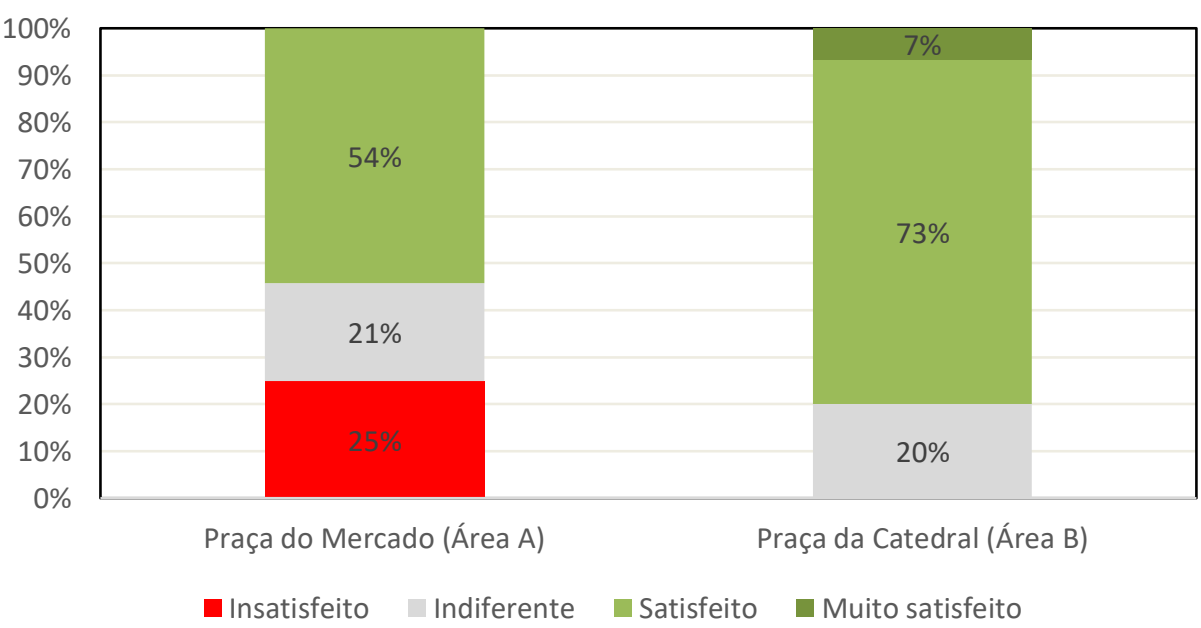

Fonte: Os autores, 2019.

Embora a Área $A$ apresente melhores condições de conforto térmico os usuários relataram maior satisfação na Área B, o que pode ser explicado pela maior velocidade do vento na 
Área A (figura 14), já que, sendo este um espaço mais aberto possui menos barreiras.

Figura 14 - Variação da velocidade do vento durante o período de coleta em cada área.
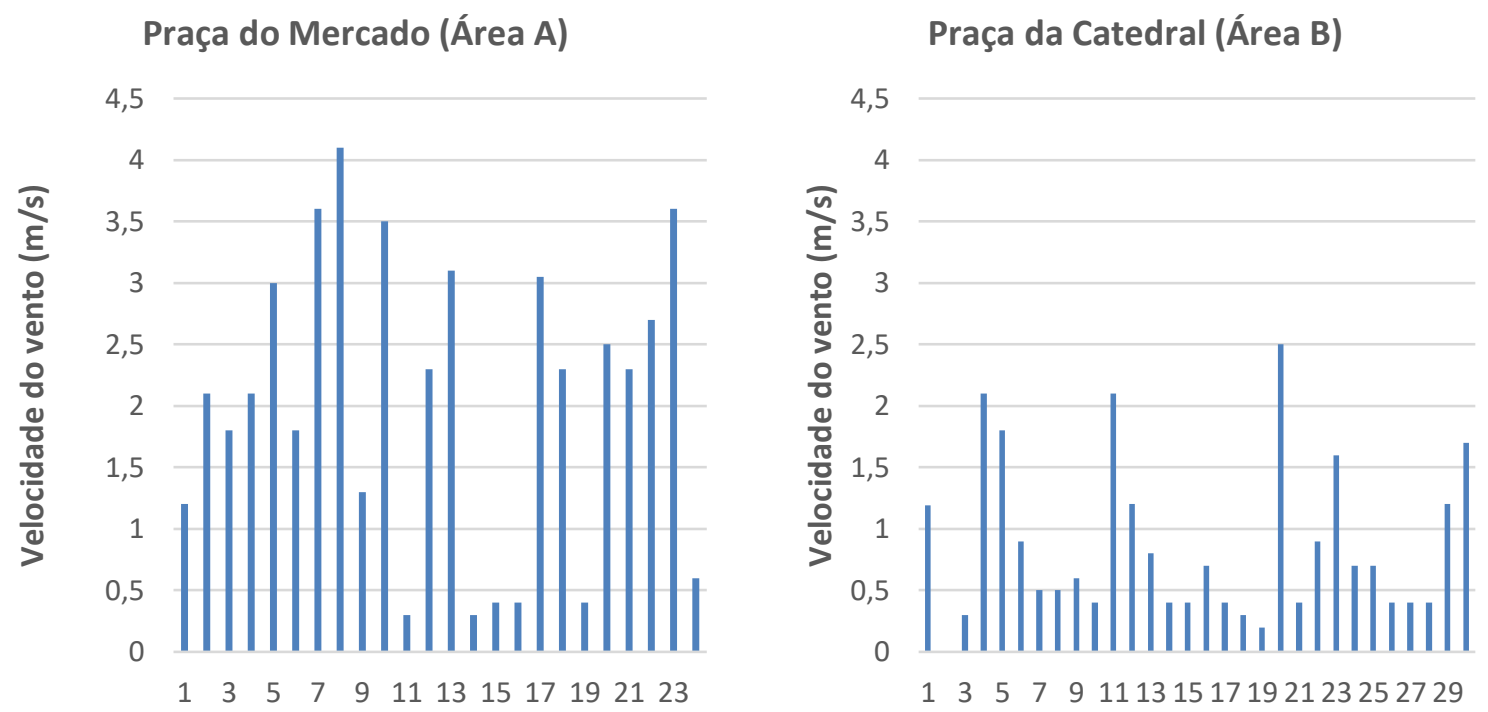

Fonte: Os autores, 2019.

\section{CONCLUSÕES}

Após as análises realizadas pode-se concluir que, em relação ao transecto móvel, a temperatura do ar não apresentou alterações consideráveis. A diminuição da temperatura observada nas duas últimas quadras, possivelmente se deu pela presença da vegetação, além de ser uma área mais aberta, com maior fluxo de vento, e com a presença do Córrego do Gregório.

Assim, o desconforto causado pelo vento durante o inverno na área A acarretou na maior satisfação dos usuários com a área $B$, ainda que $O$ nível de conforto tenha sido predominantemente de neutralidade térmica nas duas regiões.

Destaca-se ainda que a metodologia adotada cumpre seu papel na realização de uma análise prévia e sucinta do clima e conforto local, sendo necessário maior aprofundamento para uma análise mais detalhada.

\section{AGRADECIMENTOS}

Os autores agradecem à Coordenação de Aperfeiçoamento de Pessoal de Nível Superior (CAPES) por seu apoio neste trabalho, através da concessão de bolsa de pesquisa.

\section{REFERÊNCIAS}

ABREU, L. V. Avaliação Da Escala De Influência Da Vegetação No Microclima Por Diferentes Espécies Arbóreas. 2008. Tese (Mestrado em Engenharia Civil) - Universidade Estadual de Campinas. Faculdade de Engenharia Civil. Campinas, 2008.

FERNANDES, M. E.; MASIERO, E. Influência da morfologia urbana sobre a sensação de conforto térmico humano em um recorte urbano da cidade de São Carlos-SP. In:

CONGRESSO LUSO-BRASILEIRO PARA O PLANEAMENTO URBANO, REGIONAL, INTEGRADO E SUSTENTÁVEL (PLURIS), 8., 2018, Coimbra - Portugal. Anais... . Coimbra - Portugal: Pluris, 2018. p. 1 - 13. Disponível em: <https://www.dec.uc.pt/pluris2018/Paper964.pdf>. Acesso em: 13 abr. 2019 
FROTA, A. B.; SCHIFFER, S. R. 2003. Manual de conforto térmico: arquitetura e urbanismo. 7.ed. São Paulo: Studio Nobel, 243p.

GIVONI, B. Comfort, climate analysis and building design guidelines. Energy and Building, Amsterdam, v. 18, 1992.

Man, climate and architecture. 2 ed. London: Applied Science Publishers. 1976.

GOOGLE, INC. Google Earth PRO. Versão 7.3.1.4507. 2018.

HÖPPE, P. The physiological equivalent temperature - a universal index for the biometeorological assessment of the thermal environment. International Journal of Biometeorology, v. 43, n. 2, p. 71-75, 1999.

JOHANSSON, E. et al. Instruments and methods in outdoor termal comfort studies - The need for standardization. Elsevier: Urban Climate 10 (2014) 346-366. 2014.

LAMBERTS, R.; XAVIER, A. A. P. Conforto térmico e stress térmico. Universidade Federal De Santa Catarina Centro Tecnológico - Departamento De Engenharia Civil. LabEEE Laboratório de Eficiência Energética em Edificações. 2013. Disponível em: <http://dec.ufms.br/lade/docs/cft/ap-labeee.pdf>. Acesso em: 21 ago. 2018.

MAYER, H.; HÖPPE, P. Thermal comfort of man in different urban environments. In: Theoretical and Applied Climatology, v. 38, p. 43-49, 1987.

MIGUEL, R. A. D. et al. A importância do planejamento urbano e da gestão ambiental para o crescimento ordenado das cidades. $5^{\circ}$ Encontro de Engenharia e Tecnologia dos Campos Gerais. Paraná, 2009. Disponível em: <http://www.cronosquality.com/aulas/artigoplurb.pdf>. Acesso em: 12 ago. 2018.

NIKOLOPOULOU, M. H.; BAKER, N.; STEEMERS, K. Thermal Comfort in Outdoor Urban Spaces: Understanding the Human Parameter. Solar Energy, Kidlinton, v. 70, n. 3, p. 227-235, 2001.

OKE, T. R. The micrometeorology of the urban forest. Philosophical Transactions of the Royal Society of London. Series B, Biological Sciences - vol. 324, No 1223, Forest, Weather and Climate. 1989.

. Initial guidance to obtain representative Meteorological observations at urban sites. World meteorological organization, Instruments and observing methods, Report $n^{\circ} 81$. University of British Columbia. Vancouver, 2006.

ROSSI, F. A; KRÜGER, E.; NIKOLOPOULOU, M. A influência da configuração urbana no microclima e na sensação térmica em ruas de pedestre de Curitiba, Paraná. XI Encontro Nacional de Conforto no Ambiente Construído. Rio de janeiro, 2011.

RUAS, A. C. Avaliação de conforto térmico - Contribuição à aplicação prática das normas internacionais. São Paulo: FUNDACENTRO, 2001.

SHASHUA-BAR, L.; HOFFMAN, M. E. Vegetation as a climatic component in the design of an urban street An empirical model for predicting the cooling effect of urban green areas with trees. Energy and Buildings 312000 221-235. Elsevier Science. 1999.

UNIVERSITÄT FREIBURG. Meteorologisches Institut. RayMan. Version 1.2. Freiburg, 2009.Disponível em:<http://www.urbanclimate.net/rayman/index.htm>. Acesso em: 25 Março. 2009. 